\title{
Computational Fluid Dynamics Studies of Nuclear Rocket Performance
}

Robert M. Stubbs

National Aeronautics and Space Administration

Lewis Research Center

Cleveland, Ohio

Suk C. Kim

Sverdrup Technology, Inc.

Lewis Research Center Group

Brook Park, Ohio

and

Thomas J. Benson

National Aeronautics and Space Administration

Lewis Research Center

Cleveland, Ohio

Prepared for the

Conference on Advanced Exploration Initiative Technologies cosponsored by AIAA, NASA, and OAI

Cleveland, Ohio, September 4-6, 1991 


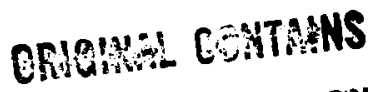 \\ COLER HUSTRATHAN
}

\section{COMPUTATIONAL FLUID DYNAMICS STUDIES OF NUCLEAR ROCKET PERFORMANCE}

\author{
Robert M. Stubbs \\ NASA Lewis Research Center \\ Cleveland, Ohio 44135 \\ Suk C. Kim \\ Sverdrup Technology, Inc. \\ Lewis Research Center Group \\ Brook Park, Ohio 44142 \\ Thomas J. Benson \\ NASA Lewis Research Center \\ Cleveland, Ohio 44135
}

\section{Summary}

A CFD analysis of a low pressure nuclear rocket concept is presented with the use of an advanced chemical kinetics, Navier-Stokes code. The computations describe the flow field in detail, including gas dynamic, thermodynamic and chemical properties, as well as global performance quantities such as specific impulse. Computational studies of several rocket nozzle shapes are conducted in an attempt to maximize hydrogen recombination. These Navier-Stokes calculations, which include real gas and viscous effects, predict lower performance values than have been reported heretofore.

\section{Background}

The president's vision of exploration missions to Mars has caused a renewed interest in nuclear propulsion systems, due to their promise of high efficiency, which derives from the enormous energy density of nuclear fuel. This renaissance of interest follows almost two decades of $R \& D$ inactivity since the cessation of nuclear rocket technology programs such as NERVA. Now, new technologies are available for the development of nuclear propulsion systems of higher performance, reliability, and safety. One of these technologies is computational fluid dynamics (CFD), which offers accurate simulations of complex fluid, chemical, and thermal behavior quickly and at relatively modest cost. One advantage of CFD simulations is the ability to screen a number of advanced concepts speedily, and then to optimize the designs of the better performers. Another advantage is the ability to replace some relatively expensive experimental testing, such as in microgravity or radioactive environments, with numerical experiments on supercomputers. This paper presents some of the first CFD simulations and analyses of hydrogen flows characteristic of solid core nuclear rockets, with an emphasis on studying dissociation effects.

A concept that has recently spurred interest in the propulsion community, because of its potential for high specific impulse and operational simplicity, is the low pressure nuclear rocket (ref. 1). This concept involves heating hydrogen gas by contact with nuclear fuel elements in a chamber at relatively low pressure, and then allowing the gas to expand through a nozzle. The chamber is maintained at a low pressure to allow a higher fraction of hydrogen molecules, $\mathrm{H}_{2}$, to dissociate than would occur at higher pressures. The lower pressure hydrogen, then, can absorb more energy per unit mass. If most of the hydrogen atoms, $\mathrm{H}$, recombine during the expansion process, the energy invested in the dissociation process can be reclaimed in the form of increased kinetic energy, or increased specific impulse. To evaluate the performance of such a rocket it is necessary to know the degree of recombination that occurs during the flow through the nozzle. The more recombination that occurs, the higher the specific impulse.

Accurate prediction of the performance of the low pressure nuclear thermal rocket requires the ability to 
compute the gas dynamic and chemical properties at every point in the flow field, a capability that did not exist until recently. For the present analysis, computations using RPLUS (ref. 2), a Navier-Stokes CFD code with chemical kinetics capability, have been conducted for several low pressure nuclear rocket configurations. These computations allow detailed analyses of the flow fields and the calculation of global properties such as thrust and specific impulse.

\section{Equilibrium and Frozen Flow Calculations}

To those used to conventional propulsion systems, lowering the chamber pressure to increase performance might seem inappropriate. However, the characteristics of interplanetary missions (large distances and relatively low gravitational losses) are such that specific impulse is the overriding figure of merit for the propulsion system. Since specific impulse is a measure of the momentum change induced per unit mass of fuel, high specific impulses translate into shorter trip times and lower fuel mass. Unlike for other, more common missions, thrust and thrust per weight are now of secondary importance as figures of merit and, therefore, high chamber pressures in themselves present no advantages. In fact, for nuclear thermal rockets, higher chamber pressures lead to lower specific impulses, as will be discussed later.

Solid core nuclear rockets are conceptually simple. A gas is heated in a chamber by contact with nuclear fuel elements, and then it is expelled through a convergingdiverging nozzle to obtain thrust. Since the specific impulse of a rocket is proportional to the speed of the effluent, good performance favors high temperatures and gasses of low molecular weight. This is the rationale for the push for higher temperature fuel elements and for the emergence of hydrogen as the propellant of choice.

Once the temperature has been maximized within constraints imposed by materials considerations, the chamber pressure remains as another parameter available to the designer to improve propulsion efficiency. Because nuclear propulsion systems have virtually unlimited supplies of energy available, it makes sense to maximize the amount of energy/enthalpy per unit mass which is invested in the hydrogen propellant, and this implies lower chamber pressures. In equilibrium mixtures of hydrogen gas at a given temperature, the mole fraction of $\mathrm{H}$ increases as the pressure decreases. This is shown in figure 1 for hydrogen at a temperature of $3600 \mathrm{~K}$. The specific enthalpy of hydrogen also increases with decreasing pressure, because energy is required to break the $\mathrm{H}_{2}$ chemical bonds. This is also shown in figure 1. Note that the increase in the specific enthalpy of hydrogen is significant as the chamber pressure, $P_{c}$, is lowered. For example, by dropping $P_{c}$ from $10 \mathrm{~atm}$. to $1 \mathrm{~atm}$., the specific enthalpy is increased
$52.3 \mathrm{~kJ} / \mathrm{g}$, and dropping $\mathrm{P}_{\mathrm{c}}$ another decade raises the specific enthalpy another $94.6 \mathrm{~kJ} / \mathrm{g}$.

The potential benefits of these higher specific enthalpies on rocket performance can be appraised by calculating the specific impulse at various chamber pressures. Such specific impulses were computed by using the NASA Lewis CET code (ref. 3), which calculates the rocket performance that would be attained by isentropic expansion from these chamber conditions. The lower curve of figure 2 shows the results of such an analysis for the so-called "frozen gas" assumption that there is no change in chemical composition after the hydrogen leaves the pressure chamber. This calculation also assumes one-dimensional, inviscid flow. In this idealized case, one can see modest increases in specific impulse, $I_{s p}$, as $P_{c}$ is lowered. For example, by dropping the chamber pressure of $3600-\mathrm{K}$ hydrogen from $10 \mathrm{~atm}$. to $0.1 \mathrm{~atm}$, the $\mathrm{I}_{\mathrm{sp}}$ increased from $1094 \mathrm{lbf}-\mathrm{sec} / \mathrm{lbm}$ to $1201 \mathrm{lbf}-\mathrm{sec} / \mathrm{lbm}$, an increase of $107 \mathrm{lbf}-\mathrm{sec} / \mathrm{lbm}$.

Another aspect of the merits of lower chamber pressures, besides the energy considerations just discussed, is that the gas has a lower molecular weight. Therefore, in this isothermal process, the gas particles are faster than hydrogen molecules. This results in a higher specific impulse during a frozen expansion. In effect, the energy required to create this propellant of lower molecular weight is freely available because of the tremendous energy capacity of the nuclear fuel. The engineering challenge is to find the most efficient and effective means of harnessing this resource.

The low-pressure concept offers a second, and greater, opportunity for performance enhancement. The first, just described, involves the ability to invest more energy per unit mass of propellant in the pressure chamber. The second opportunity lies in recombination of the $\mathrm{H}$ atoms during their expansion through the nozzle. Recombination allows the reclaiming of the energy invested in dissociating the $\mathrm{H}_{2}$ molecules, and the performance benefits of this process can be substantial.

As hydrogen expands through the nozzle, its pressure and temperature decrease. At these conditions, the equilibrium molar fraction of $\mathrm{H}_{2}$ is higher than for the conditions that existed in the pressure chamber. Therefore, there are favorable conditions in the nozzle for recombination. When $\mathrm{H}$ recombines to $\mathrm{H}_{2}$ during its acceleration through the nozzle, there are two aspects of the recombination to consider, one that lowers and one that raises propulsion efficiency. The negative aspect of recombination lies in the increase of the molecular mass. If no temperature change occurred in this process, the average speed of $\mathrm{H}_{2}$ in an equilibrium mixture would be $1 \sqrt{2}$ times the average speed of the $\mathrm{H}$ atom. Fortunately, the dissociation energy which is recovered in the recombination is sufficiently large to overcome this deficit, so that the average molecular speed after recombination is greater. The recombination process requires 3 -body collisions described in the following chemical equation: 


$$
\mathrm{H}+\mathrm{H}+\mathrm{M} \rightarrow \mathrm{H}_{2}+\mathrm{M}+\Delta \mathrm{E}
$$

Here $M$ represents $\mathrm{H}$ or $\mathrm{H}_{2}$. The energy released by this recombination, $\Delta \mathrm{E}$, represents the increase in the propellant's total enthalpy.

If, during the flow through the rocket, equilibrium conditions were reached at all locations, maximum propulsion benefits would accrue from hydrogen recombination. Calculations were performed using the same CET code for an idealized nozzle at equilibrium conditions to obtain the upper bound for performance levels of the low-pressure nuclear thermal rocket concept. The upper curve of figure 2 shows, as a function of pressure in the $3600 \mathrm{~K}$ chamber, the specific impulse which would be attained if equilibrium could be reached in the hydrogen flow. This curve shows the striking increases in specific impulse as chamber pressure is decreased. By dropping $P_{c}$ from $10 \mathrm{~atm}$. to 0.1 atm., for example, $I_{s p}$ increases from $1262 \mathrm{lbf}-\mathrm{sec} / 1 \mathrm{bm}$ to $1680 \mathrm{lbf}-\mathrm{sec} / \mathrm{lbm}$, an increase of $418 \mathrm{lbf}-\mathrm{sec} / \mathrm{lbm}$. Recall that for the frozen flow calculations the increase over this same range of $P_{c}$ is only $90 \mathrm{lbf}-\mathrm{sec} / \mathrm{lbm}$. If viscous and multidimensional effects are ignored, the two curves of figure 2 represent upper and lower bounds of performance. The lower curve assumes infinitely long reaction times, while the upper curve assumes instantaneously fast reaction rates. More accurate calculations require the consideration of the finite rate of the chemical kinetics, as well as the considerations of the viscous nature of real gasses and the geometries of real rockets.

\section{Chemical Kinetics Calculations}

After seeing the potential benefits that low chamber pressures promise, it is unfortunate for the rocket designer that the times required to achieve equilibrium at various locations in the nozzle are relatively long. As temperature and density fall, the probability that the three-body interactions will occur drops drastically. How far performance falls below the ideal of equilibrium flow will depend on reaction rates, the speed of the hydrogen gas, and the dimensions of the rocket. For a more realistic assessment of the lowpressure concept for applications to space exploration, calculations were performed for a rocket of dimensions and conditions similar to those used in studies at the Idaho National Engineering Laboratory (ref. 1). Their analysis specified a rocket with a throat diameter of $0.56 \mathrm{~m}$, an overall length of $8 \mathrm{~m}$, an approximate throat-to-exit length of $6.5 \mathrm{~m}$, and an area expansion ratio of 40 . The calculations performed here used the same throat size, a throat-to-exit length of $7.56 \mathrm{~m}$, and an expansion ratio of 100 .

The first calculation for this geometry, with hydrogen as a propellant, was performed by using LSENS (ref. 4), a one-dimensional, inviscid gas dynamic rocket code with finite rate kinetics. When applied to the above nozzle, with the same chamber conditions used in the calculations of figure 2 (i.e., $T c=3600 \mathrm{~K}, P_{c}=1 \mathrm{~atm}$.), the resulting specific impulse was $1237 \mathrm{lbf}-\mathrm{sec} / \mathrm{lbm}$. This value is 100 lbf-sec/lbm higher than the frozen-flow calculation, but $233 \mathrm{lbf}-\mathrm{sec} / \mathrm{lbm}$ less than the equilibrium-flow calculation. This indicates that the residence time of hydrogen in the nozzle, approximately $1 \mathrm{msec}$, was insufficient for significant recombination to take place.

\section{Navier-Stokes Simulations}

Although useful information can be gleaned from the previous calculations which can help help to identify potentially strong candidate propulsion concepts, the simplifying assumptions of one-dimensional, inviscid, frozen or equilibrium flow leave several uncertainties. Fortunately, computational capability now exists, unavailable when nuclear propulsion technology was first developed three decades ago, which can accurately simulate these nuclear rocket flows. To compute all of the relevant gas dynamic, chemical, thermodynamic and performance properties of these hot hydrogen flows, we have used an advanced CFD code, RPLUS (ref. 2), developed at the Lewis Research Center, which solves the full Navier-Stokes equations, coupled with the finite rate chemical kinetics equations. Although this code has three-dimensional capability, the axisymmetric nature of these rockets required only the twodimensional version. The use of this code, which has been used previously (refs. 5 to 8 ) to calculate the flow fields of various rocket nozzles, allows the calculation of all quantities of interest at any point in the flow field.

The RPLUS calculations presented are for a thruster with the same length, throat diameter, and area ratio used in the LSENS calculation. Since that earlier analysis was for one-dimensional, inviscid flow, no nozzle contour was specified. The first configuration studied here, labeled nozzle A, has a contour derived from a Rao optimization procedure (ref. 9). The radius of curvature of the nozzle wall just downstream of the throat is equal to the radius of the throat, the area expansion ratio is 100 , and the throatto-exit length is $7.56 \mathrm{~m}$. The wall contour for nozzle $A$ is shown in figure 3 . The code was run with a grid of over 14,000 points, 239 elements in the axial direction, 60 in the radial direction. The grid points were clustered near the wall and throat, where flow gradients are highest.

Figure 4(a) shows iso-Mach contours, in the nozzle A flow field, for a 3600-K chamber temperature and a 1-atm. chamber pressure. The specific impulse calculated for this case is $1166 \mathrm{lbf}-\mathrm{sec} / \mathrm{lbm}$, which is $72 \mathrm{lbf}-\mathrm{sec} / \mathrm{lbm}$ less than the value calculated by the inviscid, one-dimensional kinetics code. The lower performance values from the NavierStokes calculations are due to viscous losses, predominantly in the boundary layer at the nozzle wall. The boundary layer is easily observed as a high gradient region in the 
contour plot. Another interesting feature observable in figure 4(a) is the compression wave that is generated at the inflection point of the nozzle wall a small distance downstream of the throat.

Figures 4(b) and 4(c) show isocontours of static temperature and $\mathrm{H}_{2}$ mass fraction, respectively, for nozzle $A$. Figure 4(c) indicates that little hydrogen recombination occurs once the flow has reached the regions of high expansion downstream of the throat. Because of the large performance benefits, discussed earlier, which accrue from recombination, this suggests that there might be merit to studying a nozzle which expands more gradually after the nozzle throat. This would allow hydrogen to dwell longer in states of higher pressure and density where recombination is more likely to occur. Accordingly, two more nozzle contours, nozzles $B$ and $C$, obtained by lengthening the throat region, were analyzed. These contours were generated with the Rao procedure (ref. 9), using the same length and area ratio, and radii of curvature for the wall near the throat of 10 and 100 times the throat radius. The wall contours of nozzles $\mathrm{B}$ and $\mathrm{C}$ are also shown in figure 3, where they can be compared with the baseline case, nozzle A. The effects of these modifications on the flow fields can be seen in figures 5(a) and 5(b), where the iso-Mach number contours of nozzles $\mathrm{B}$ and $\mathrm{C}$, respectively, are shown. The calculations show that lengthening of the throat region tends to move the compression wave closer to the nozzle wall.

Figures 6 to 9 show axial distributions of Mach number, velocity, static temperature, and $\mathrm{H}_{2}$ mass fraction, respectively, at the centerlines of the three nozzles. As expected, the Mach numbers and velocities of nozzles B and C increase less rapidly after the throat because of their less severe expansions. Note that although the Mach number of nozzle $\mathrm{A}$ is considerably higher than that of nozzle $\mathrm{C}$ at the exit, their velocities are almost the same there. This is because the exit static temperature of nozzle $A$ is lower than that of nozzle $C$, as can be seen in figure 8 . The higher temperatures in nozzles B and C would, by themselves, tend to slow the recombination process compared to that of Nozzle A if their pressures were the same. Because RPLUS solves the kinetics and gas dynamics equations in a coupled fashion, the competing effects of higher pressure, which tends to augment recombination, and higher temperature, which tends to discourage recombination can be resolved. Figure 9 indicates that the optimization strategy does indeed promote more recombination earlier in the nozzle. At $\mathrm{X}=2.5 \mathrm{~m}$, for example, the $\mathrm{H}_{2}$ mass fraction in nozzle $\mathrm{C}$ is approximately 1.4 percent higher than at that position in nozzle A. By the time the flow has reached the exit, however, the advantage has dropped to 0.3 percent.

Figures 10 to 14 show the radial distributions, at the nozzle exits, of Mach number, total velocity, radial velocity, static temperature, and $\mathrm{H}_{2}$ mass fraction of the three nozzles. Although the centerline Mach number of Nozzle $\mathrm{A}$ is highest, figure 10 shows that it decreases near the nozzle wall where it becomes the least of the three. The total velocity distribution in figure 11 shows almost equal values in the center regions. Closer to the wall, however, nozzles $\mathrm{B}$ and $\mathrm{C}$, with progressively longer throat regions, produce higher velocity flows. Not all of the increased total velocity benefits thrust, however, as can be seen in figure 12, which shows the increased radial velocities of nozzles $B$ and $C$. The larger radial velocity components, which do nothing to help propulsion, are due to the larger wall exit angles, listed in table I, associated with the stretched throat nozzles. The temperature profiles, shown in figure 13 , revcal higher temperatures near the centerline for nozzles $B$ and $C$, with the reverse being the case when the radial distance has increased through the compression region of each nozzle. The high temperatures in the boundary layers are consistent with the adiabatic wall boundary condition assumption and the low velocity flow there. The $\mathrm{H}_{2}$ mass fractions at various radial positions in the exit flow are shown in figure 14. Clearly, the throat stretching technique produces higher degrees of recombination with larger differences appearing in the outer rings.

To study the effect of the shape modifications on the composition of the total mass flow, calculations were made of the total $\mathrm{H}_{2}$ mass flow rate and the total mass flow rate at the exits of each nozzle. The ratio of $\mathrm{H}_{2}$ mass flow to total mass flow at the exit was $69.11,69.84$, and 70.20 percent for nozzles $\mathrm{A}, \mathrm{B}$, and $\mathrm{C}$, respectively. In this case, throat lengthening did produce a total recombination enhancement.

Although these studies of the flow field provide important information which leads to a better understanding of the flow physics, the rocket designer is interested, ultimately, in global performance information. Specific impulse, as discussed earlier, is the most important figure of merit for nuclear propulsion systems. The specific impulse of the baseline nozzle A, as calculated by RPLUS, was 1166.4 $\mathrm{lbf}-\mathrm{sec} / \mathrm{lbm}$. Lengthening the throat region in nozzle B resulted in a value of $1169.4 \mathrm{lbf}-\mathrm{sec} / \mathrm{lbm}$, a small improvement of $3 \mathrm{lbf}-\mathrm{sec} / \mathrm{lbm}$. When that strategy was carried further in nozzle $\mathrm{C}$, the specific impulse dropped $2 \mathrm{lbf}$-sec/lbm to $1167.4 \mathrm{lbf}-\mathrm{sec} / \mathrm{lbm}$, most likely due to increased divergence angle of the flow field in the outer rings. The fact that, even with the higher recombination, nozzle $\mathrm{C}$ had lower specific impulse than nozzle B illustrates the need to use codes that can calculate losses due to compression waves, boundary layers, and other fluid dynamic processes.

\section{Conclusions}

Some straightforward techniques were used to enhance rocket performance. The use of an advanced CFD code allowed calculation of the effects of these design modifications 
on the flow field and performance. The message that emerges from these Navier-Stokes chemistry calculations is that real losses are significant and that simple calculations assuming equilibrium, one-dimensional, inviscid flow lead to overly optimistic performance values. There are rocket codes that are useful in design that do not employ full CFD simulations of the flow field, but these are only useful within their experience data base. Since CFD codes, such as RPLUS, solve the relevant equations of motion and chemistry at all grid points in a coupled fashion, they can be used throughout the entire Reynolds number range, even in design areas that have never been tested. Another conclusion from this analysis is that improvements in the low-pressure concept by innovative nozzle designs will probably be modest at best without some form of externally imposed hydrogen recombination enhancement techniques.

The ability of advanced CFD codes to calculate detailed information throughout the flow field as well as integrated performance values provides rocket designers with a new and powerful capability. This analysis of the low-pressure nuclear propulsion concept has demonstrated some of these capabilities in the hope that CFD will be used to a greater extent in the design process to provide propulsion systems of higher performance, lower cost, and higher reliability.

\section{References}

1. Ramsthaler, J.H., et al: Low Pressure Radial Flow Nuclear Rocket Concept (LPNTR). Nuclear Thermal Propulsion: A Joint NASA/ DOE/DOD Workshop, NASA CP-10079, 1991.

2. Shuen, J.-S.; and Yoon, S.: Numerical Studies of Chemically Reacting Flows Using a LU-SSOR Scheme. AIAA J., vol. 27, no. 12, Dec., 1989, pp. 1752-1760.

3. Gordon, S.; and McBride, B.J.: Computer program for Calculation of Complex Chemical Equlibrium Compositions, Rocket Performance, Incident and Reflected Shocks, and Chapman-Jouguet Detonations. NASA SP-273, 1976.

4. Radhakrishnan, K.; and Bittker, D.A.: LSENS - A General Chemical Kinetics and Sensitivity Analysis Code for Gas-Phase Reactions: User's Guide. NASA TM-105851, 1993.

5. VanOverbeke, T.J.; and Shuen, J.-S.: A Numerical Study of Chemically Reacting Flow in a Nozzle. NASA TM-102135, 1989.

6. Kim, S.C.; and VanOverbeke, T.J.: Calculations of Gaseous $\mathrm{H}_{2} / \mathrm{O}_{2}$ Thrusters. AIAA Paper 90-2490, July 1990.

7. Kim, S.C.: Numerical Study of High-Area-Ratio $\mathrm{H}_{2} / \mathrm{O}_{2}$ Rocket Nozzles. AIAA Paper 91-2434, June 1991.

8. Reed, B.D., et al: Experimental and Analytical Comparison of Flowfields in a $110 \mathrm{~N}$ (25 lbf) $\mathrm{H}_{2} / \mathrm{O}_{2}$ Rocket. AIAA Paper 91-2283, June 1991.

9. Nickerson, G.R.,; Dang, A.L.; and Dunn, S.S.: The Rao Method Optimum Nozzle Contour Program. NASA Contract NAS8-36863, 1988.

\section{Acknowledgements}

The authors wish to thank B.J. McBride and D.A. Bittker for their assistance with the equilibrium, frozen and finite rate calculations. The work of the second author, S.C. Kim, was supported by NASA Lewis Research Center under Contract NAS3-25266

TABLE I.-NUCLEAR ROCKET SPECIFICATION AND PERFORMANCE SUMMARY [Chamber temperature, $T_{c}, 3600 \mathrm{~K}$; chamber pressure, $P_{c}, 1 \mathrm{~atm}$.]

\begin{tabular}{|l|c|c|c|c|c|c|}
\hline $\begin{array}{l}\text { Flow } \\
\text { condition }\end{array}$ & $\begin{array}{c}\text { Throat-to-exit } \\
\text { length, } \mathrm{m}\end{array}$ & $\begin{array}{c}\text { Throat } \\
\text { diameter, } \mathrm{m}\end{array}$ & $\begin{array}{c}\text { Area } \\
\text { ratio }\end{array}$ & $\begin{array}{c}\text { Exit wall } \\
\text { angle, deg }\end{array}$ & $\begin{array}{c}\text { Specific impulse, } \\
\mathrm{I}_{\text {sp, }}, \mathrm{lbf}-\mathrm{sec} / \mathrm{bm}\end{array}$ & $\begin{array}{c}\text { Average mass } \\
\text { fraction of } \mathrm{H}_{2} \\
\text { at nozzle exit }\end{array}$ \\
\hline Frozen & N.A. & N.A. & N.A. & N.A. & 1136.5 & 0.6564 \\
Equilibrium & N.A. & N.A. & N.A. & N.A. & 1469.8 & .9494 \\
Finite rate & 7.56 & N.A. & 100 & N.A. & 1236.7 & .7238 \\
Nozzle A & 7.56 & 0.56 & 100 & 7.70 & 1166.4 & .6911 \\
Nozzle B & 7.56 & .56 & 100 & 11.06 & 1169.4 & .6984 \\
Nozzle C & 7.56 & .56 & 100 & 13.46 & 1167.4 & .7020 \\
\hline
\end{tabular}




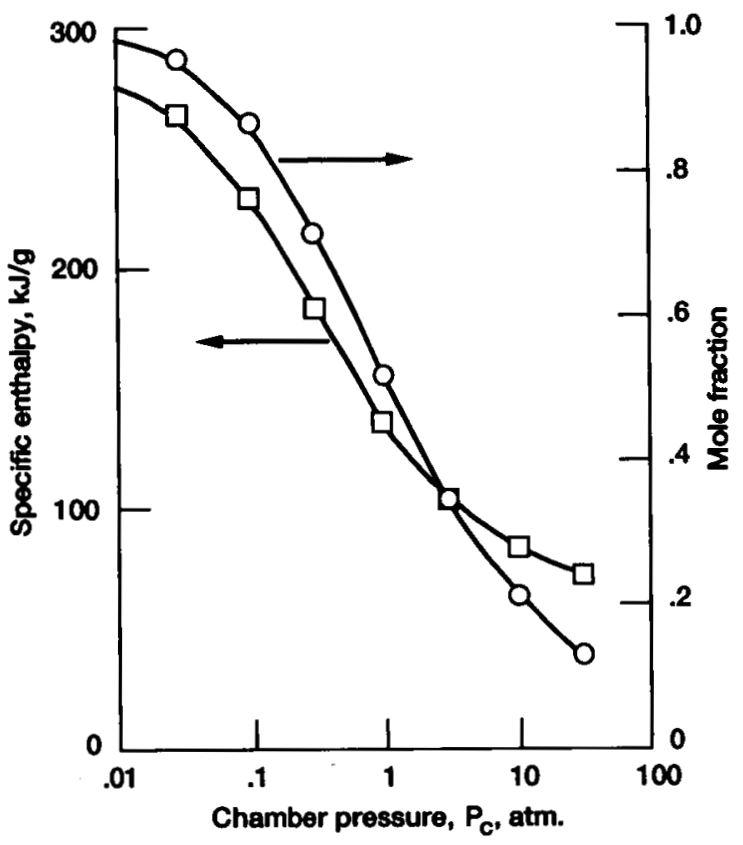

Figure 1. - Specific enthalpy and mole fraction of monatomic hydrogen as functions of chamber pressure. Hydrogen temperature, $3600 \mathrm{~K}$.

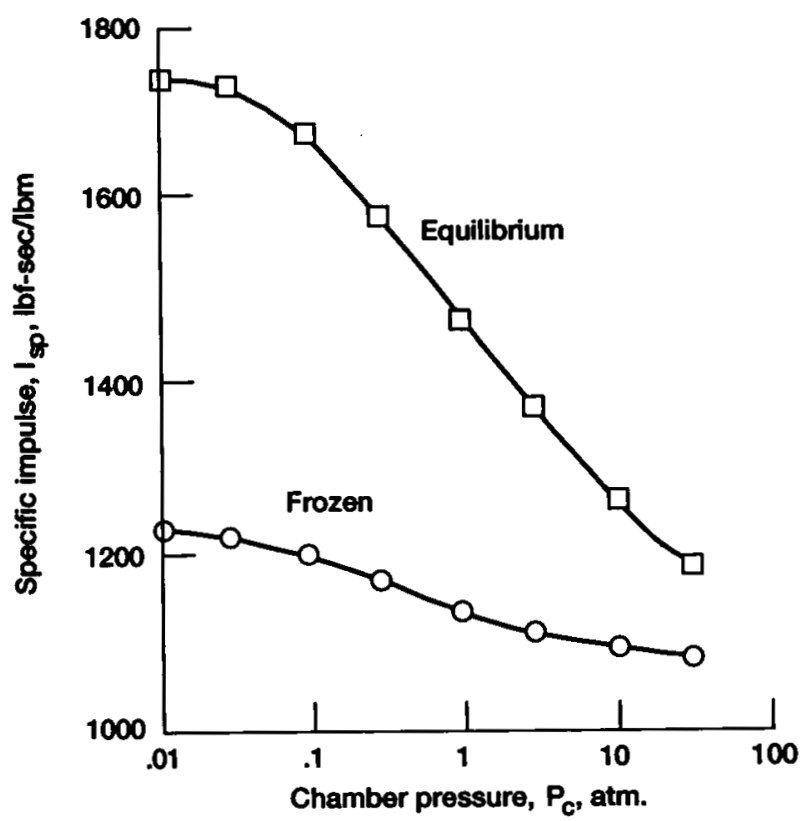

Figure 2.-Specific impulse as function of chamber pressure for rocket using hydrogen propellant. Hydrogen temperature, $3600 \mathrm{~K}$. One-dimensional, inviscid flow assumptions used.

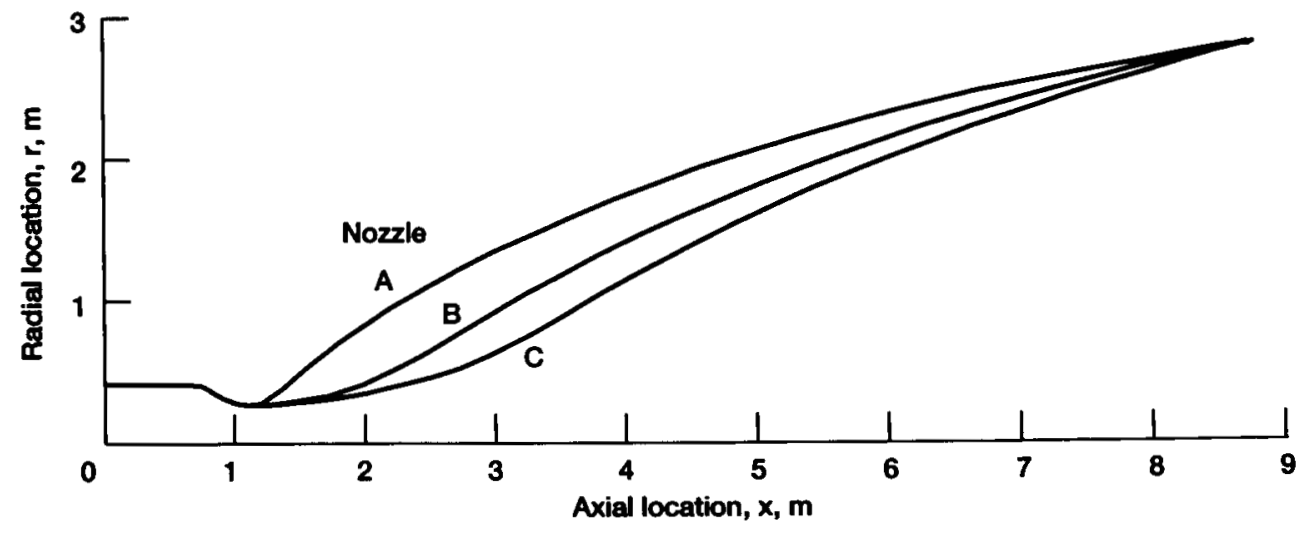

Figure 3.-Wall contours of axisymmetric nozzles A, B, and C. Throat diameter, $0.56 \mathrm{~m}$; throat-toexit length, $7.56 \mathrm{~m}$; and area expansion ratio, 100 . 


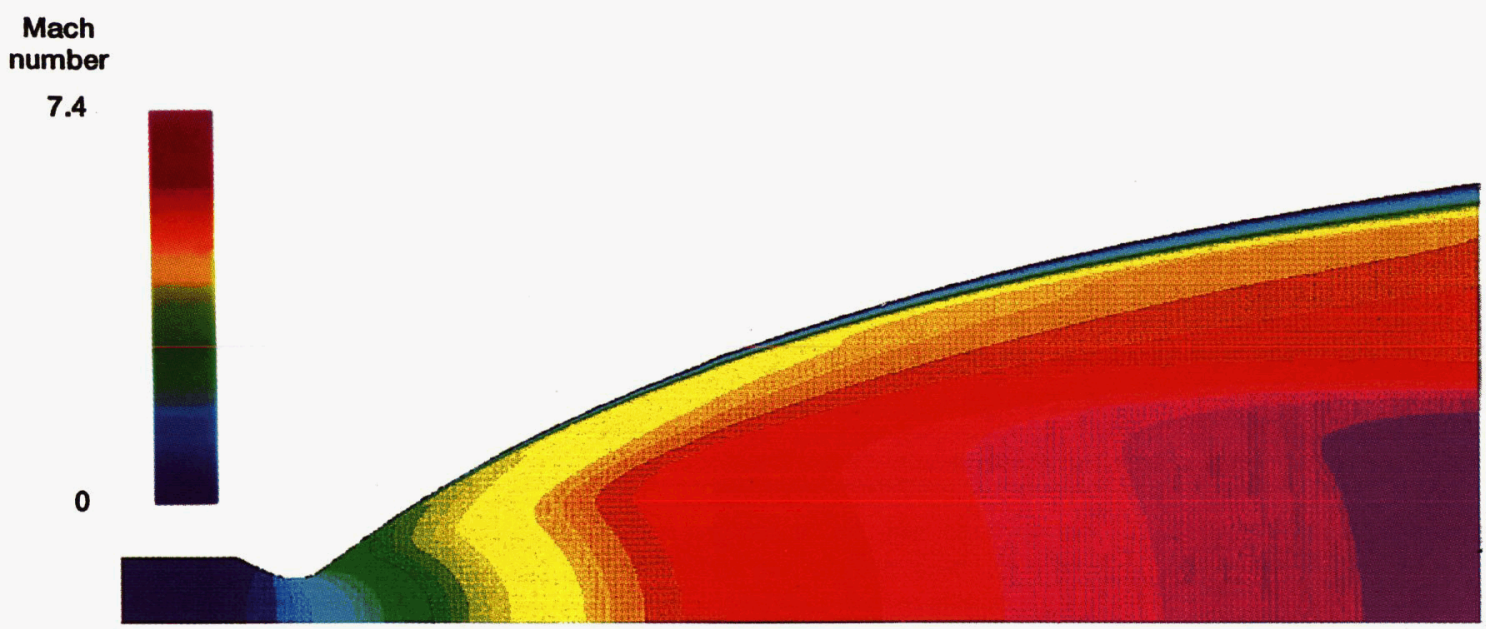

(a) Mach number.

Static

temperature,

K

3600

300

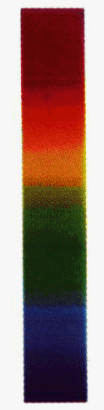

(b) Static temperature.

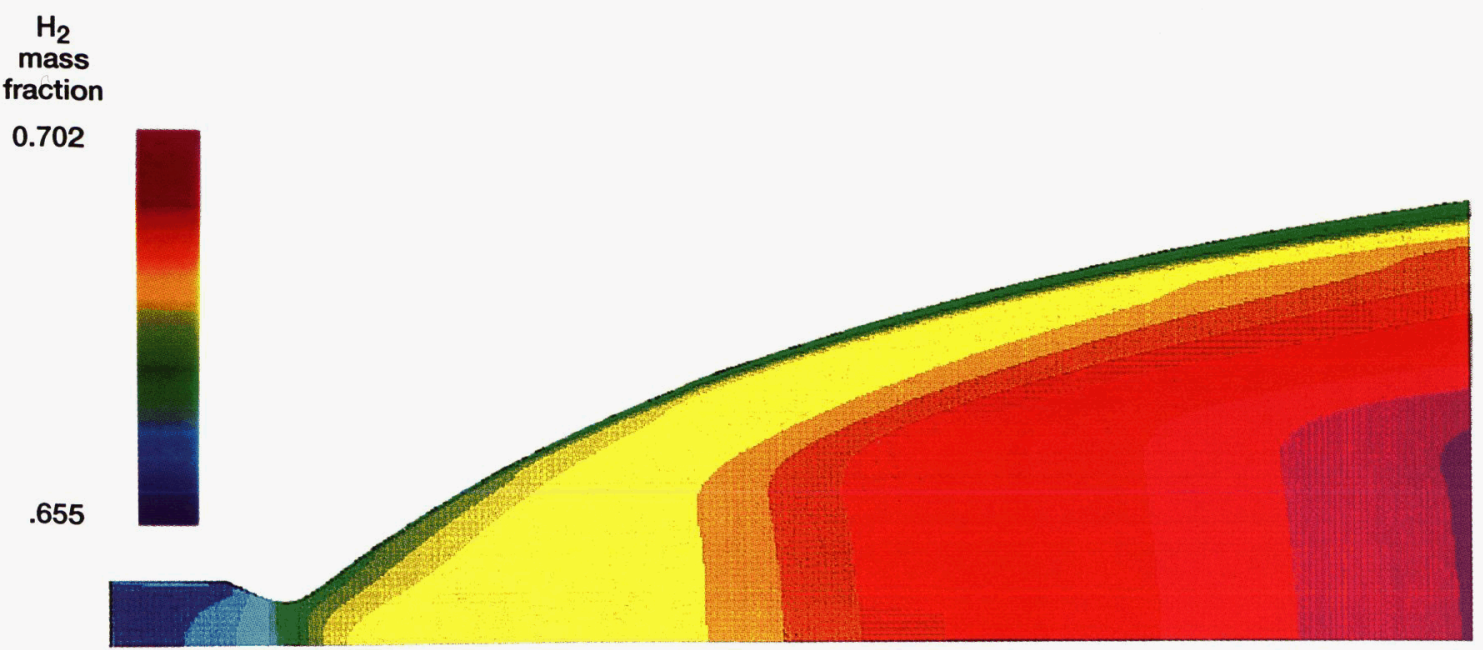

(c) Mass fraction.

Figure 4.-Contours of equal Mach number, static temperature, and mass fraction of molecular hydrogen, $\mathrm{H}_{2}$, in the fiow fieid of nozzle $A$. 


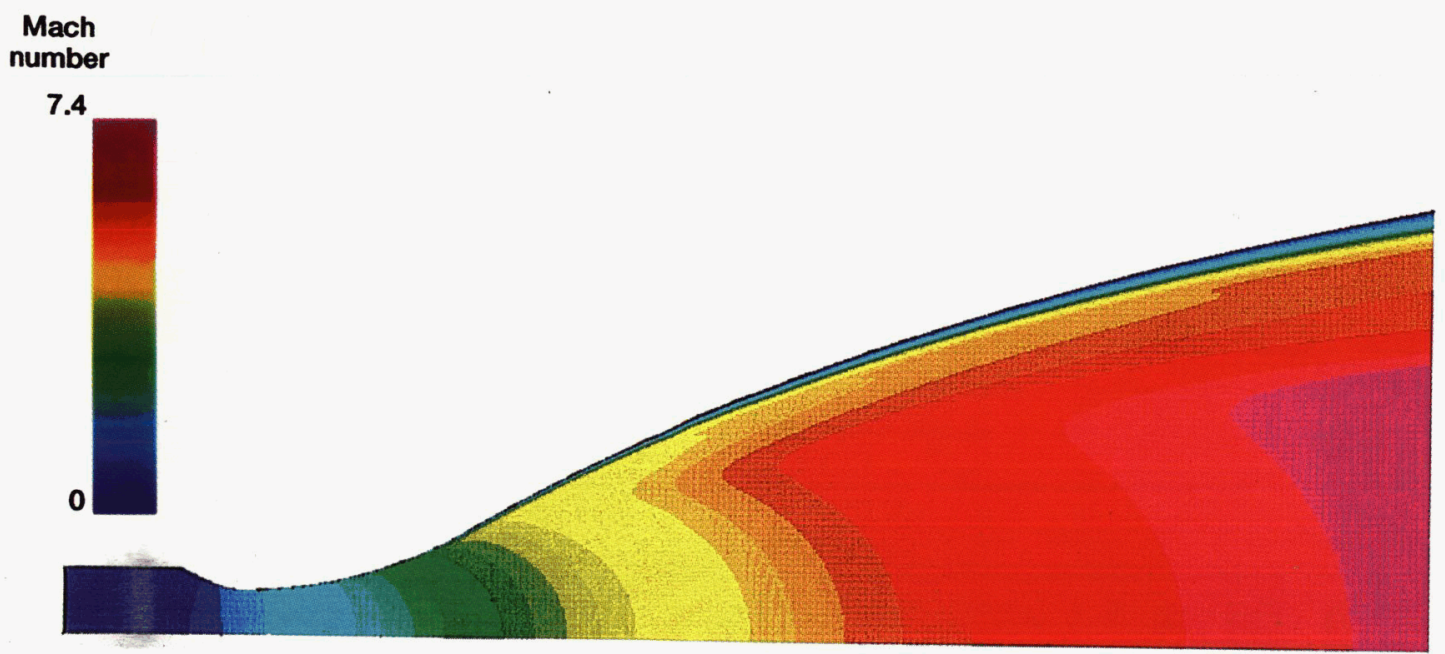

(a) Nozzle B.

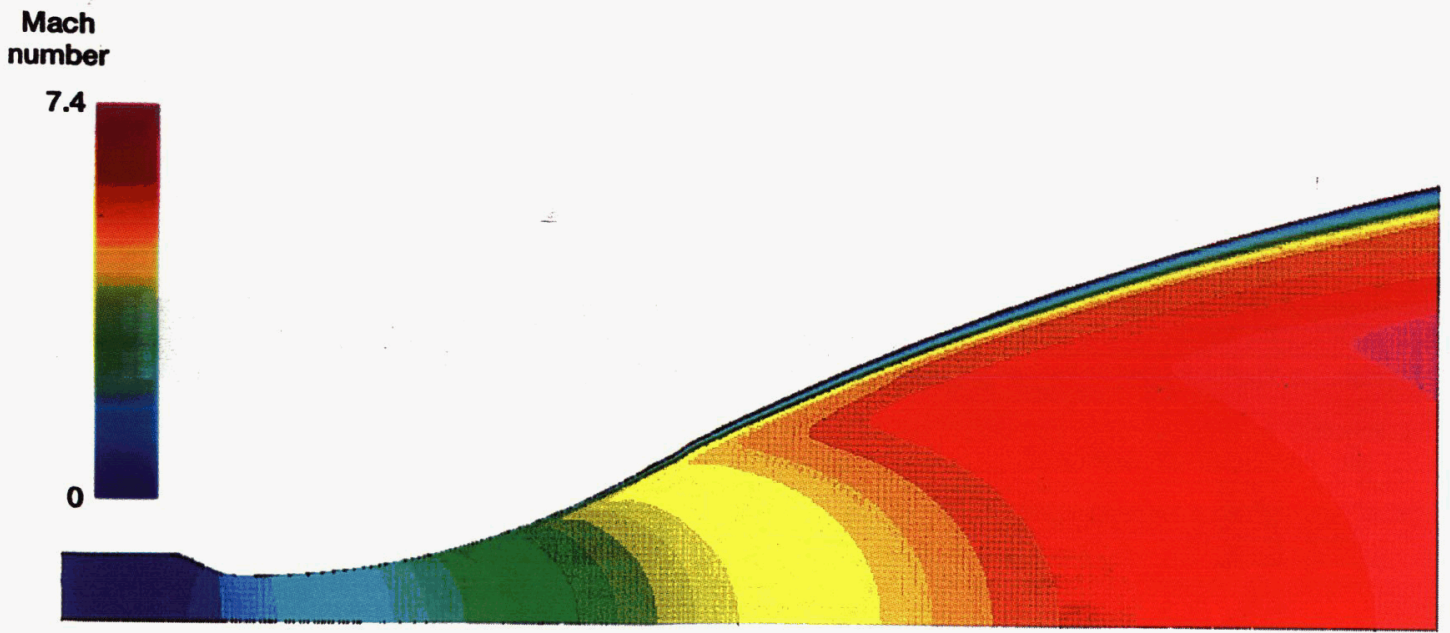

(b) Nozzle C.

Figure 5.-Contours of equal Mach number for nozzles $B$ and $C$. 


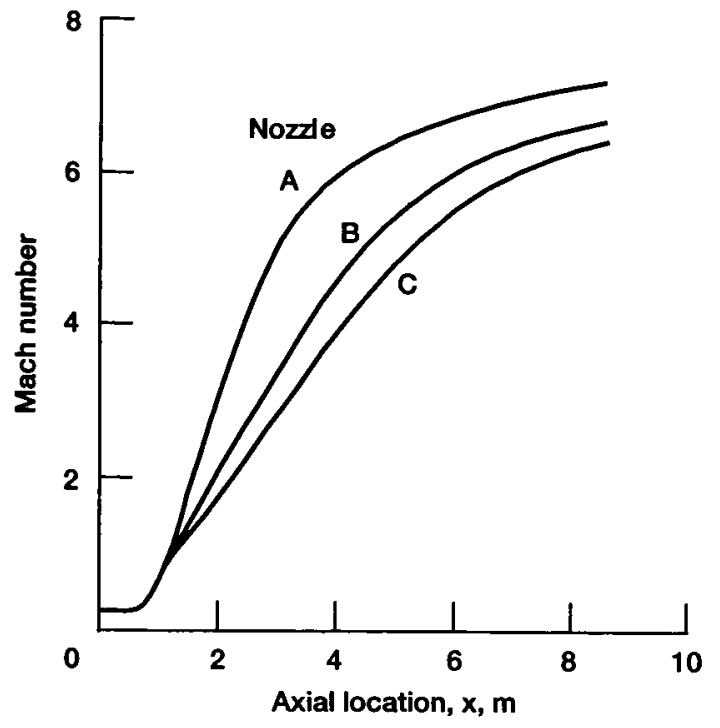

Figure 6.-Axial distributions of Mach number on centerlines of nozzles.

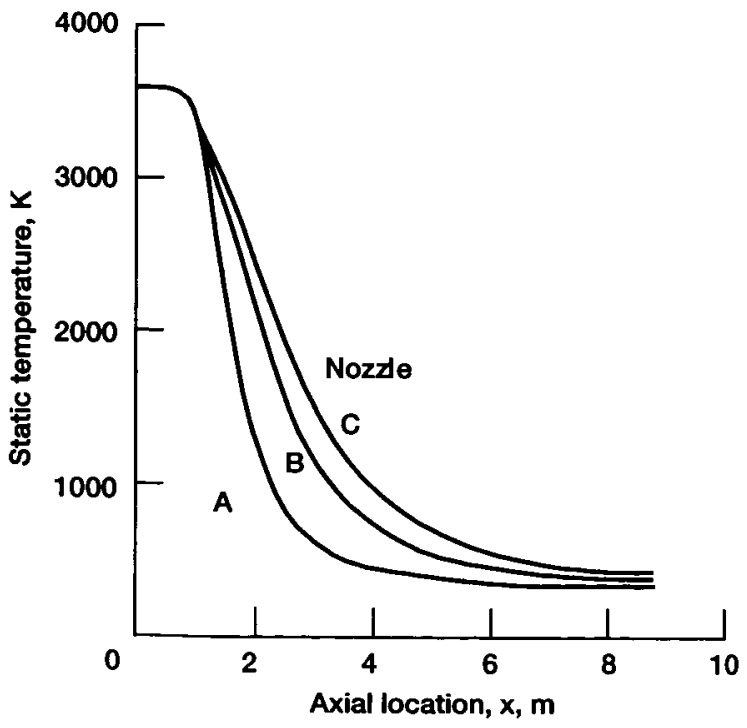

Figure 8.-Axial distributions of static temperature on centerlines of nozzles.

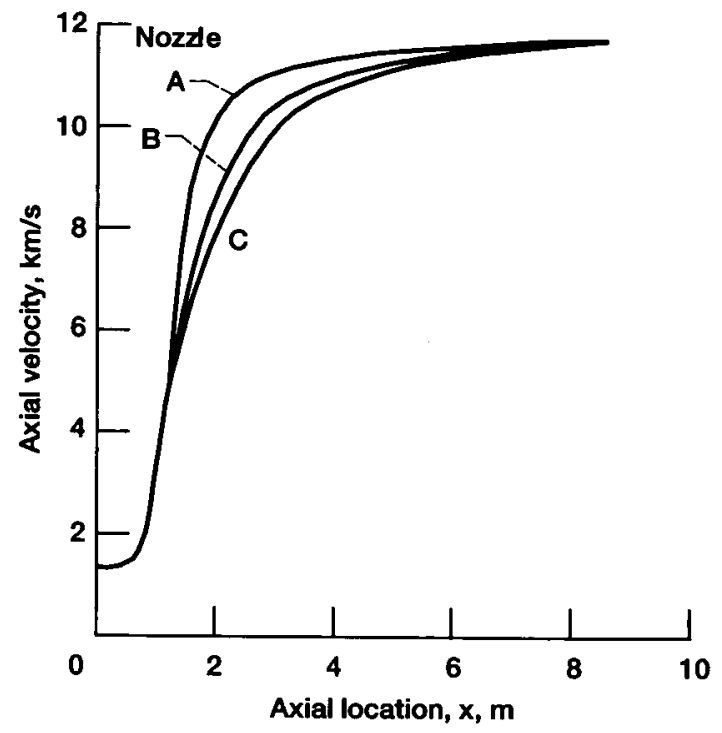

Figure 7.-Axial distributions of velocity on centerlines of nozzes.

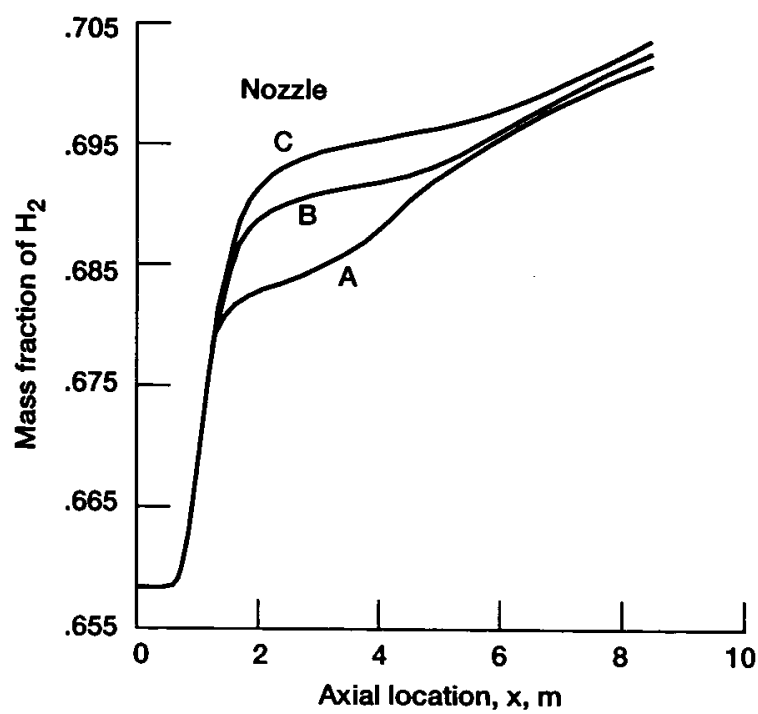

Figure 9.-Axial distributions of mass fraction of $\mathrm{H}_{2}$ on centerlines of nozzles. 


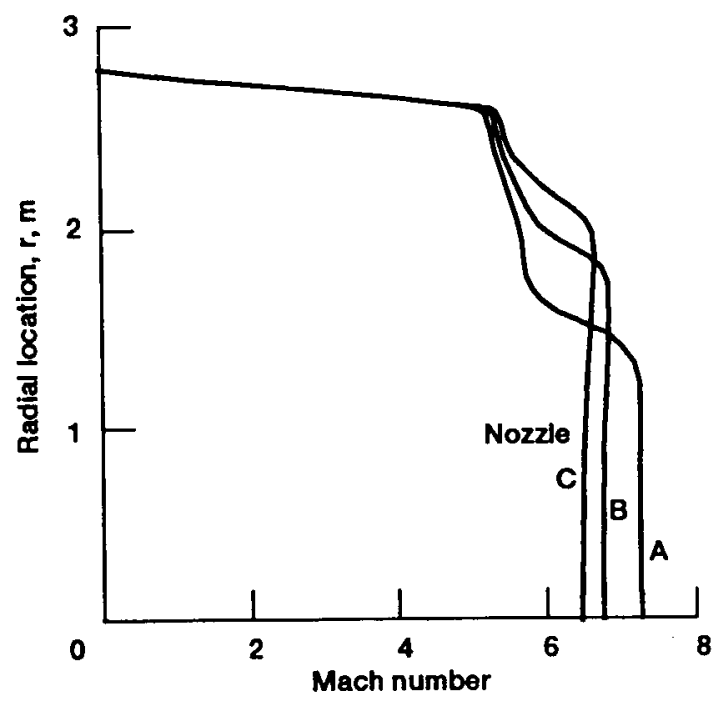

Figure 10.-Radial distributions of Mach number at exits of nozzles.

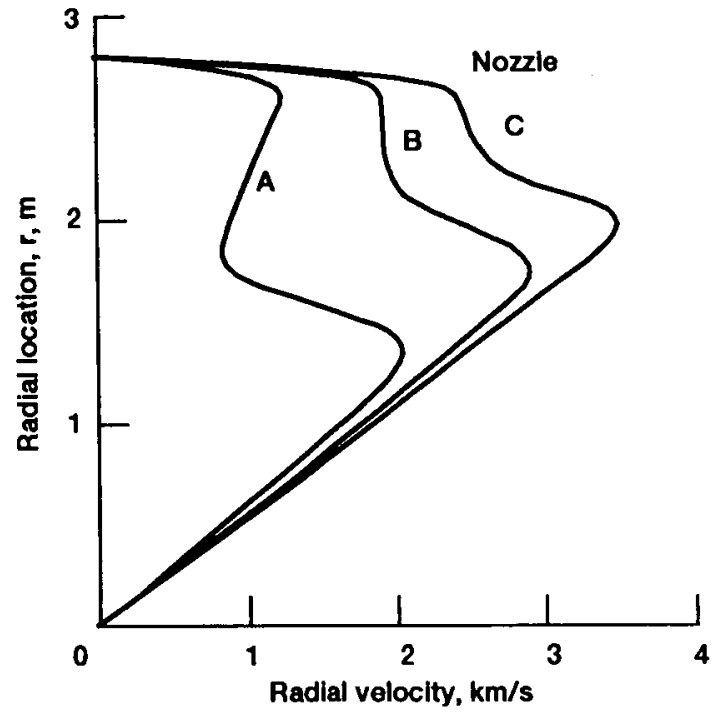

Figure 12.-Radial distributions of radial velocity at exits of nozzles.

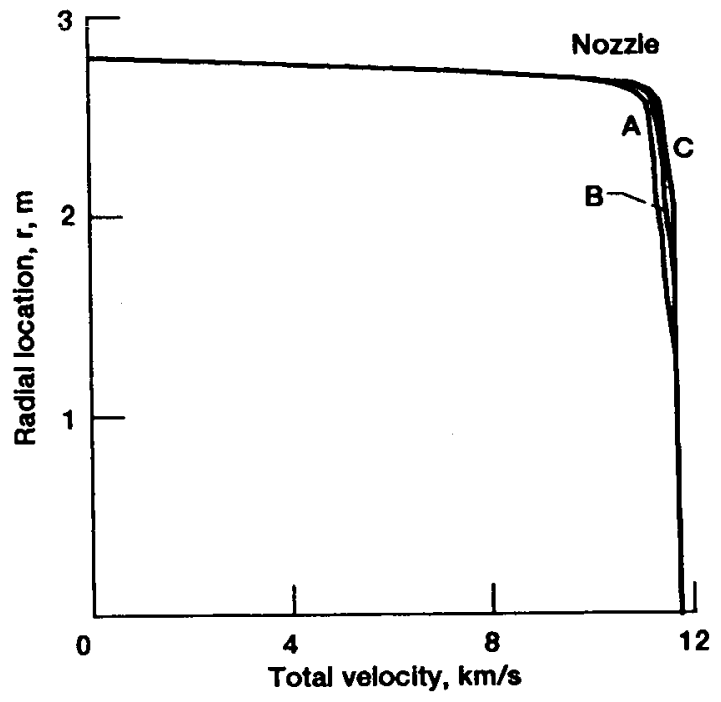

Figure 11.-Radial distributions of total velocity at exits of nozzles.

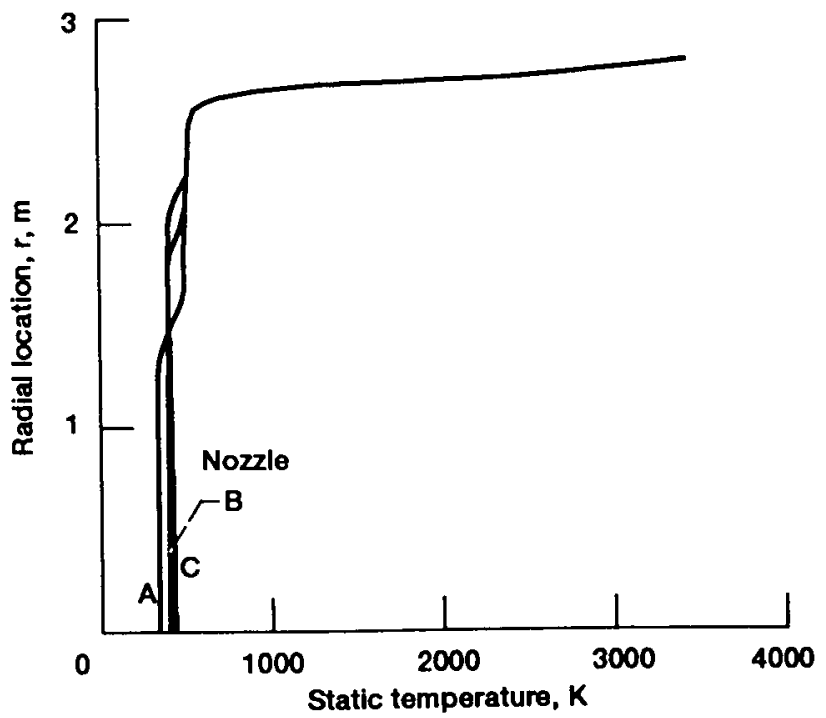

Figure 13.-Radial distributions of static temperature at exits of nozzles. 


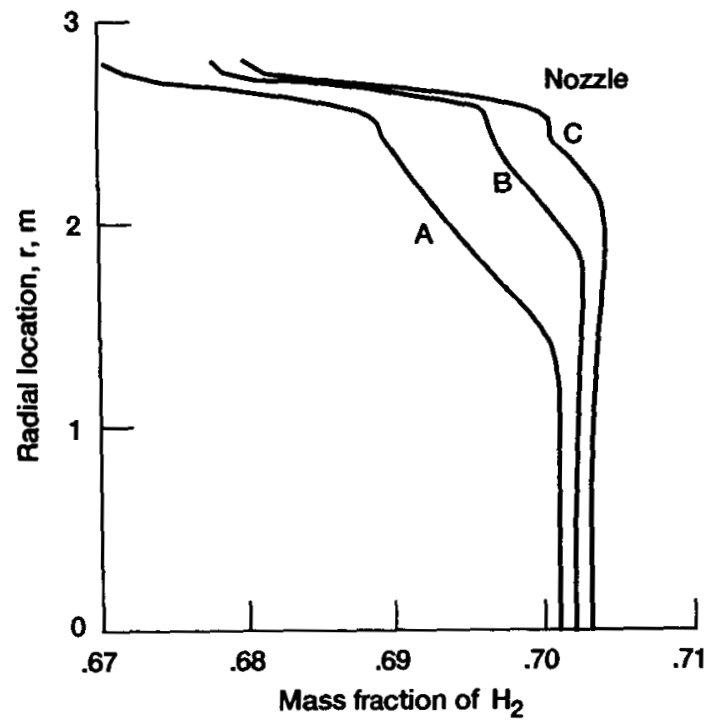

Figure 14.--Radial distributions of mass fraction of $\mathrm{H}_{2}$ at exits of nozzles. 
Public reporting burden for this collection of intormation is estimated to average 1 hour per response, including the time for reviewing instructions, searching existing data sources, gathering and maintaining the data needed, and completing and reviewing the collection of information. Send comments regarding this burden estimate or any other aspect of this collection of information, including suggestions for reducing this burden, to Washington Headquarters Services, Directorate for information Operations and Reports, 1215 Jeflerson Davis Highway. Suite 1204, Arlington, VA 22202-4302, and to the Office of Management and Budget, Paperwork Reduction Project (0704-0188), Washington, DC 20503.

\begin{tabular}{|l|l|l}
\hline 1. AGENCY USE ONLY(Leaveblank) & $\begin{array}{c}\text { 2. REPORT DATE } \\
\text { June } 1994\end{array}$ & $\begin{array}{r}\text { 3. REPORT TYPEAND DATESCOVERED } \\
\text { Technical Memorandum }\end{array}$ \\
\hline
\end{tabular}

4. TITLEAND SUBTITLE

Computational Fluid Dynamics Studies of Nuclear Rocket Performance

6. AUTHOR(S)

Robert M. Stubbs, Suk C. Kim, and Thomas J. Benson

\section{FUNDING NUMBERS}

WU-505-62-52

\section{PERFORMING ORGANIZATION NAME(S)AND ADDRESS(ES)}

National Acronautics and Space Administration

Lewis Research Center

Cleveland, Ohio 44135-3191
8. PERFORMING ORGANIZATION REPORT NUMBER

E-6858
9. SPONSORING/MONITORING AGENCY NAMES(S)AND ADDRESS(ES)

National Aeronautics and Space Administration

Washington, D.C. 20546-0001
10. SPONSORING/MONITORING AGENCY REPORT NUMBER

NASA TM-105436

\section{SUPPLEMENTARY NOTES}

Prepared for the Conference on Advanced Exploration Initiative Technologies cosponsored by AIAA, NASA, and OAI, Cleveland, Ohio, September 4-6, 1991. Robert M. Stubbs and Thomas J. Benson, NASA Lewis Research Center, and Suk C. Kim, Sverdrup Technology, Inc., Lewis Research Center Group, 2001 Aerospace Parkway, Brook Park, Ohio 44142. Responsible person, Robert M. Stubbs, (216) $433-6303$.

12a. DISTRIBUTION/AVAILABILITY STATEMENT 12b. DISTRIBUTION CODE

Unclassified - Unlimited

Subject Categories 20 and 34

\section{ABSTRACT (Maximum 200 words)}

A CFD analysis of a low pressure nuclear rocket concept is presented with the use of an advanced chemical kinetics, Navier-Stokes code. The computations describe the flow field in detail, including gas dynamic, thermodynamic and chemical properties, as well as global performance quantities such as specific impulse. Computational studies of several rocket nozzle shapes are conducted in an attempt to maximize hydrogen recombination. These Navier-Stokes calculations, which include real gas and viscous effects, predict lower performance values than have been reported heretofore.

14. SUBJECT TERMS

Nuclear propulsion; Computational fluid dynamics; Hydrogen recombinations

\section{SECURITY CLASSIFICATION OF REPORT \\ Unclassified}

\author{
18. SECURITY CLASSIFICATION \\ OF THIS PAGE \\ Unclassified
}

19. SECURITY CLASSIFICATION OFABSTRACT Unclassified 